\title{
LA NATURE CHEZ D'AUBIGNÉ
}

Quel était 1 'héritage culturel de 1 'homme baroque? Mélange de raison, d'intuition, de mythes, sa manière de penser n'était certes pas la nôtre. Son attitude vis-à-vis de la nature était différente aussi. L'homme du seizième siècle vivait très près de 1a nature. I1 était imprégné de ses odeurs, de ses sons, de ses couleurs. Il l'aspirait de tous ses sens à un tel point qu'il ne semblait plus former qu'un tout et alors 1 a

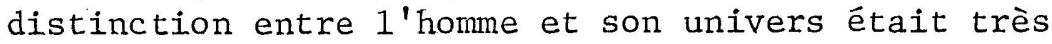
floue. C'est dans la nature que le poète puisait ses métaphores, ses images. I1 pouvait observer son inconstance, son dynamisme, la vie puissante qui l'agite constamment. Créée par Dieu, fragment de l'étincelle divine, la nature était le témoin constant de la bonté de Dieu envers sa créature, 1 'homme.

Théodore-Agrippa d'Aubigné (1552-1630), soldatcourtisan-poète, commença la rédaction des Tragiques en 1578. I1 enrichit cette oeuvre au cours des années et il la publia en 1616. Dans 1'introduction de cette oeuvre, I'Auteur à son Livre, d'Aubigné nous expose son but. Il se voit un peu comme un orophète chargé d'une mission: réformer une société qui vient de traverser une période particulièrement riche en événements politiques et religieux qui ont eu des résultats tragiques et néfastes. Son oeuvre étant surtout satirique et morale, d'Aubigné se range un peu à part des poètes baroques. L'univers du moraliste est I'homme. Ainsi les descriptions de la nature que nous trouvons chez les 1yriques baroques, SaintAmant en particulier, ne se trouvent pas chez un écrivain dont le but n'est pas de décrire, plaire, mais d'instruire. Le thème de la nature, 
par conséquent, se trouve relégué à une position secondaire dans les Tragiques.

Dès le début de son poème d'Aubigné semble vouloir se placer sous le signe protecteur de la Nature: "Astres, secourez-moi."1 I1 ne doute même pas de la présence de la nature, de sa bienveillance foncière. Elle est là, mais voudra-telle lui répondre? Quelques vers plus loin, nous voyons tout de suite qu'il ne s'agit déjà plus d'une "sympathie" entre 1 'homme et son univers, mais d'une relation toute personnelle: "ô mère" (p. 54) lui dit-il "et le fruit de ton flanc fait le champ du combat." Le lien étroit entre 1'homme et la Nature est tout de suite établi. Les horreurs des guerres de religion ne vont pas se produire sur les terres d'une nature indifférente à ce qui 1 'entoure mais sur le corps d'un être humain. Cette personnification provoque chez le lecteur un sentiment d'horreur, d'inhumanité: non seulement 1 'homme lui-même est massacré, mais 1 a vie de sa mère, création divine, est mise en danger. N'est-ce pas Dieu lui-même que 1 'homme, dans sa folie, attaque: "Pour me vouloir tuer, premièrement vous tue." (p. 60).

Le sentiment entre 1 a nature et 1 'homme fait chez d'Aubigné tout de suite explosion et dépasse toutes les bornes. Voilà la nature dotée de sa propre vie. Tout comme un être humain, elle aura ses propres sentiments. Le lien entre la Nature et $1^{\prime}$ 'homme sera comparable à celui de la mère pour son enfant. Elle souffrira pour lui et par lui. Nous savons aussi que cette mère "n'aime pas le sang, ni les ordures" (p. 59) ce qui laisse présager qu'elle ne sera peut-être pas aussi impassible que nous pourrions le supposer. 
Le corps de cette Nature est mutilé, outragé, les membres sont retranchés. Son haleine même est corrompue et nous 1 a voyons tituber dans 1 'espace rendue finalement ivre, inhumaine par toutes ces horreurs. Toute beauté disparaî̀t quand à leur tour "Les fleurs perdent d'un coup la vie et les couleurs" (p. 79).

L'enfant profanateur a attenté à la vie de sa mère. Dieu même en ressent le coup et pour montrer son mécontentement "Le haut ciel s'obscurcit, cent mille tremblements/Confondirent la terre et les trois éléments" (p. ४3). Cette étroite relation entre 1 'homme, la nature et Dieu se trouve illustrée dans bien des passages rendant ainsi le crime d'autant plus grand.

Quel visage offre la terre à son Dieu? Forêts ravagées, moissons détruites, fleuves rouges de sang, tout n'est que ruines, horreurs. Cette terre bouleversée, ruinée prend soudainement un visage imprévu. De bonne qu'elle était, "légère et plus douce que miel" (p. 204) elle devient maléfique. Dieu même semble vouloir renier sa création quand "Il se repentit donc d'avoir formé la terre" (p. 234) et il la quitte.

Sous cet anathème, le monde se renverse. Tout comme CaIn lorsqu'il commit son horrible crime, la Nature fuit, transie d'effroi, tremblante dans un univers qu'elle ne comprend plus ou les feuilles, les rameaux et les fleurs deviennent des poignards, où le "Vent, ne purge plus 1'air" (p. 298), où au lieu de pluie le Ciel envoie du sang et de la poudre et où enfin la mere enfle les monts et "La terre s'en creva" (p. 322).

Dans son arrogante fierté, I'homme a oublié le principe universel: Dieu, lNature et pensée (p. 344). $L$ 'homme a réduit tout en cendre et il en souffrira 


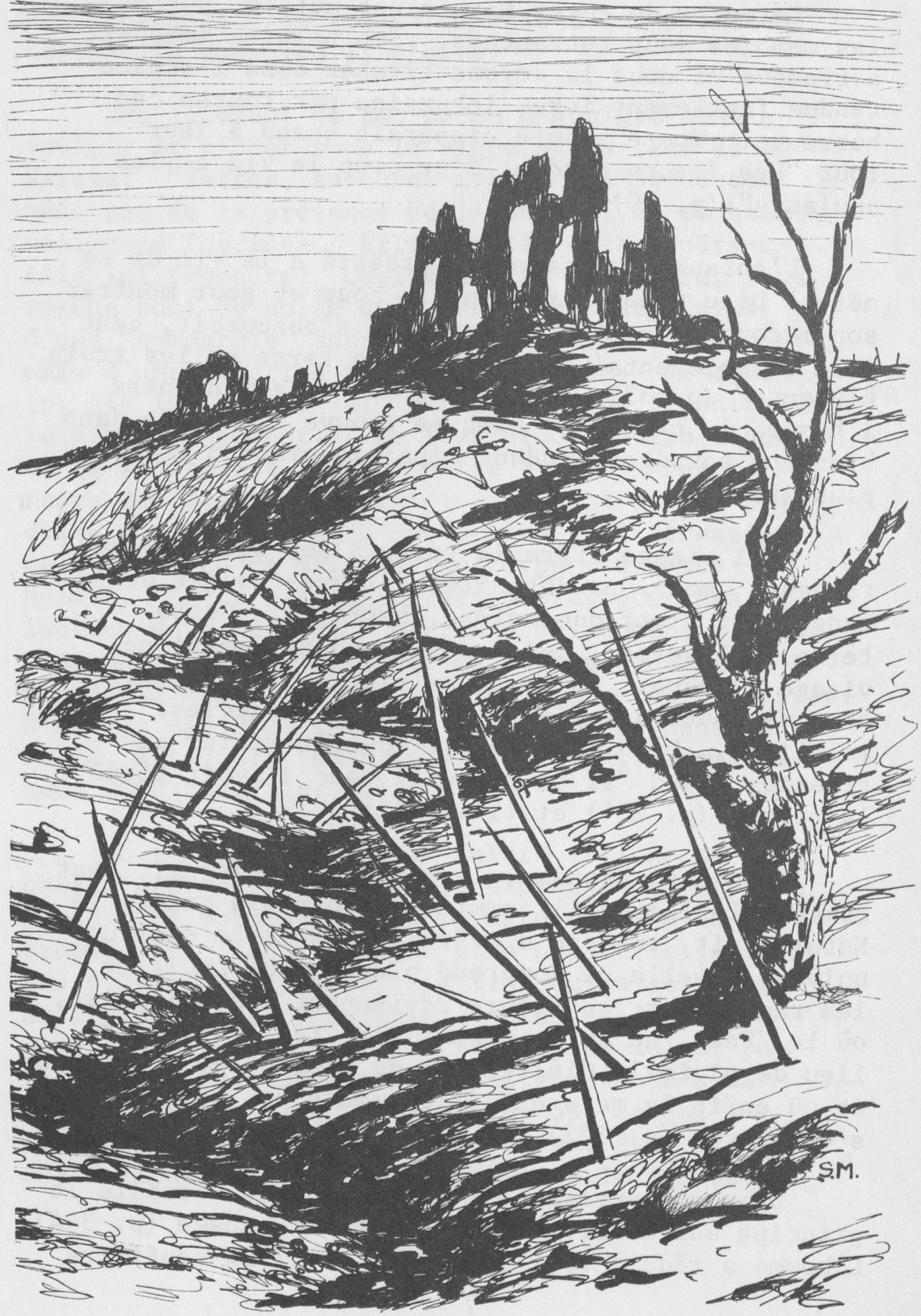


les conséquences. Le voilà de nouveau chassé du paradis terrestre. Pourtant les foudres de l'ire divine ne seront pas éternelles. Dieu, dans sa grande bonté, aura pitié de sa Création et de sa Créature. Le soleil radieux viendra bientôt réchauffer cette nature morte et les hommes, en extase de joie, admireront encore "Cette terre nouvelle, et ce grand ciel nouveau" (p. 357). Le monde sera enfin rendu à la paix et la Nature sera revêtue d'une parure nouvelle et de splendeur éternelle (p. 363). L'univers entier reprendra sa condition pure: les hommes, les plantes, les fruits renaitront sans vices. Les yeux humains n'auront jamais "Vu pareilles beautés ni si vives couleurs" (p. 367) et 1'homme extatique devant tant de beautés se pâmera.

Nous pouvons tirer quelques conclusions de la courte analyse de ces passages en ce qui concerne l'usage thématique de la nature dans les Tragiques. Tout d'abord, la nature, telle que la décrit le poète, n'est jamais décrite pour elle-même. Comme nous 1 'avons déjà indiqué, pour ìe moraliste, le réformateur, les problèmes de la vie morale lui font oublier la nature en ce qu'elle a de descriptif, de purement esthétique.

Par I'intermédiaire de métaphores viriles et d'images puissantes, le poète crée un lien d'une affinité profonde, presque morale, entre $1^{\text {'honme et }}$ la Nature, procédé qui nous révèle une conception particulière que le poète a pour son univers. Il y a entre la Nature, 1 'homme et le Créateur une relation symbiotique qui dans les Tragiques prend un earactère apccalyptique puisque nous assistons éventuellement à $1 \mathrm{a}$ fin du monde et au jour du Jugement Dernier. Sans oublier pour cela le rôle didactique de $1^{\prime}$ oeuvre, nous pouvons nous permettre de dire que pour $1^{\prime e ́ c r i v a i n ~ l a ~ n a t u r e ~ e s t ~ u n ~ v a s t e ~ r e g i s t r e ~}$ 
à la gloire de Dieu. Dans les Tragiques, d'Aubigné nous démontre amplement sa vision universelle: si 1 'homme n'observe pas les règles fixées par la Nature (Dieu, par extension) il y a une rupture d'équilibre entre 1'homme et son cosmos et ce déséquilibre entraîne - son tour des bouleversements, des calamités. Dans les Tragiques 1'homme, en violant 1a Nature, mère nourricière par excellence puisqu'il tient tout d'elle, a rompu l'ordre cosmique, naturel, humain.

Si l'homme perd toute son humanité, la Nature à son tour prend un visage inconnu et, de bonne qu'elle était, se métamorphose en un monde de malédiction. La matière étant, de par son essence, divine, 1 'homme fait ainsi violence à Dieu et celui-ci doit sévir. Cette vision cosmique reflète 1 'angoisse intérieure du poète. Pour lui, peu importe si le sang qu'il voit couler est humain ou si c'est la sève d'un arbre. La provocation est la même: il y a tentative de meutre et le poète se sent obligé d'accuser, de frapper le coupable: Il le fait avec succès dans les Tragiques.

Raymonde Britt

\section{Notes}

$1_{\text {Théodore-Agrippa d'Aubigné, Les Tragiques }}$ (Lausanne: Editions Rencontre, 1966). Toutes les citations sont tirées de ce texte. 